
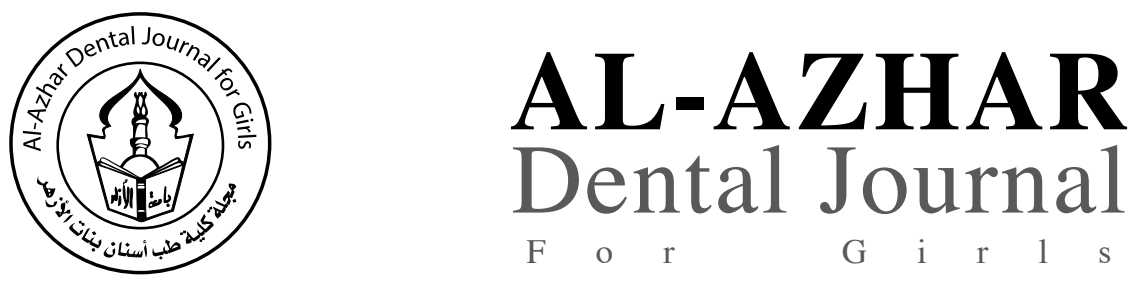

The Official Publication of The Faculty of Dental Medicine For Girls, Al-Azhar University F o r $\begin{array}{lllllllllll} & \mathrm{G} & \mathrm{i} & \mathrm{r} & \mathrm{l} & \mathrm{s}\end{array}$ Cairo, Egypt.

ADJ-for Grils, Vol. 4, No. 1, January (2017) — PP. 13:21

\title{
Effect of Different Types of Luting Cements on Retention and Marginal Adaptation of Implant-Supported Crowns (An in Vitro Study)
}

\author{
Heba Mohamed Ahmed ${ }^{(1)}$, Atef Fathy ${ }^{(2)}$ and Eman Essam ${ }^{(3)}$
}

Codex : 03/1701

dentaljournal.forgirls@yahoo.com

\section{KEYWORDS}

Implant supported crowns,

Retention, Marginal accuracy.

\begin{abstract}
Aim: The purpose of this study was to evaluate the retention values and marginal adaptation of implant- supported metal copings using different luting agents.

Material and Method: Forty implant fixtures and solid abutments of $7 \mathrm{~mm}$ height were embedded vertically in epoxy resin blocks. Metal copings with a loop on the occlusal surface were fabricated using base metal alloy. The copings were luted using four different cements (Multilink N, Fuji Plus, Fuji1 and Adhesor) under static load of $5 \mathrm{~kg}(\mathrm{n}=10)$. All specimens were subjected to 1000 thermal cycles between $5^{\circ} \mathrm{c}$ and $55^{\circ} \mathrm{c}$ with a dwell time of 10 seconds in a thermocycling device. Marginal accuracy was detected before and after cementation of all specimens by stereomicroscope. The Tensile force required to dislodge the copings were determined by a computer controlled universal testing machine with a cross-head speed of $0.5 \mathrm{~mm} / \mathrm{min}$. The force in Newton(N) required to remove the copings was recorded. Data was collected and statistically analyzed.
\end{abstract}

Results: Multilink N and Fuji1 had the highest and the least mean retentive strength respectively. There was no significant difference between MultilinkN, Fuji Plus and Adhesor. The absolute marginal discrepancies of cements were in reducing order zinc phosphate, resin modified glass ionomer, glass ionomer and resin cement.

Conclusion: within the conditions of this study, resin cement, the resin modified glass ionomer and zinc phosphate had statistically the same retentive quality and are recommended for definitive cementation of single implant-supported restoration. Different luting media had a definite effect over the final fit of all metal copings, but they were all within the clinically accepted level of $100 \mu \mathrm{m}$.

1. A Dentist in El Sahel Teaching Hospital, Cairo, Egypt.

2. Professor of Fixed Prosthodontics, Faculty of Dental Medicine, Al-Azhar University, Cairo, Egypt.

3. Assistant professor of Fixed Prosthodontics, Faculty of Dental Medicine, Al Azhar University, Cairo, Egypt. 


\section{INTRODUCTION}

Dental Implantology has revolutionized the treatment modality for replacing missing single or multiple teeth with implant supported crown/ prostheses. The range of implant indications has significantly widened. Their use often represents a better alternative over traditional options of tooth replacement. The long-term predictability of dental implants is well documented ${ }^{(1)}$.

The success and longevity of fixed restorations are the result of a number of factors. However, two factors are of primary importance: retention that defines correct and permanent position of the fixed restoration in situ and marginal seal that enables adaptation of the restoration and surfaces of the abutment. Among numerous determinants responsible for the quality of retention and marginal seal, cement characteristics used for cementing of the fixed restorations enabling intimate contact between the surfaces of abutment and fixed restorations are to be particularly emphasized.

Paper extracted from thesis entitled Effect of Different Types of Luting Cements on Retention and Marginal Adaptation of Implant-Supported Crowns (An in Vitro Study).

One hundred years ago, selection of a luting agent was easy with the availability of essentially only one luting agent, zinc phosphate cement. Currently, a plethora of luting agents is available. Now the choice of the optimal luting agent can be confusing, even for the most experienced clinician. Restorations of metal, porcelain fused to metal, lowand high-strength ceramics, full or partial coverage, require a prudent approach and the proper cement selection should be based on knowledge of physical properties, biological properties and other attributes both restorative materials and luting agents ${ }^{(2)}$.

Resin, glass ionomer and zinc oxide cements are some of the more readily available and widely used materials for traditional crown and bridge procedures. These types of cements are now employed clinically in cementing crowns to implant abutments. Subsequently, research into their properties and performance when used with implant systems is required to provide recommendations on their use ${ }^{(3)}$.

The purpose of this study was to evaluate the effect of different types of luting cements on retention and marginal adaptation of implant-supported crowns. The null hypothesis tested was that there would be no differences in retentiveness and marginal adaptation of cement retained implant-supported crowns cemented with the different luting agents.

\section{MATERIALS AND METHODS}

Forty tapered screw implants (DENTIS Co., Ltd., \#951, Woram-Dong, Dalseo-Gu, Daegu, Korea) were used in this study with $14 \mathrm{~mm}$ length and $4.8 \mathrm{~mm}$ upper diameter. Forty internal hex unmodified abutments were used with $7 \mathrm{~mm}$ length and chamfer finishing line.

The implant screws were embedded in copper cylinders $(2 \mathrm{~cm}$ height\& $2 \mathrm{~cm}$ diameter) filled with epoxy resin using a dental surveyor. The implant abutment screws were torqued to $35 \mathrm{Ncm}$ using the screw driver and ratchet (supplied by the manufacturer). Screws were subsequently retightened to 35 $\mathrm{Ncm}$ after 10 minutes to compensate for the settling effect ${ }^{(3)}$.

The abutment screw access channels were filled with compacted cotton pellets and sealed flush with the occlusal surface with softened and compacted modeling wax $^{(3)}$.

\section{Construction of cast crown}

The metal copings were made using prefabricated burn-out caps for crowns. A rounded wax sprue was shaped as a loop and was attached to the occlusal 
surface of the caps. The loop was made to provide a connection for the tensile testing machine.

A wax sprue of $3 \mathrm{~mm}$ diameter and $5 \mathrm{~mm}$ length was attached directly to the thickest part of the pattern. The wax patterns were invested in phosphate bonded investment material under vacuum and vibrator. After complete setting of the investment ring, wax elimination was performed. Electrically controlled induction casting machine was used for casting the alloy. The coping was then divested. The internal surfaces of copings were inspected for surface irregularities using magnifying lens and smoothened with a $1 / 2$ round carbide bur.

\section{Sandplasting}

The internal surface of each coping was airborneparticle abraded with $50-\mu \mathrm{m}$ aluminum oxide at 50 psi with $10 \mathrm{~mm}$ distance (Korox50, Bego, Brmen, Germany).

Castings were seated over implant-abutment assemblies and were numbered for the purposes of identification during cementation procedures.

\section{Cementation:}

Zinc phosphate cement (Adhesor) (SpofaDenta la.s.Markova238,CZ-506 46 Jiçín,Czech Republic) was mixed according to the manufacturer's instructions then painted by a plastic instrument into the casting walls leaving the occlusal surface free to decrease the hydrostatic pressure during seating.

The copings were then seated on their corresponding implant abutment assemblies using finger pressure then $5 \mathrm{Kg}$ load for 10 minutes by using load applicator device. After complete setting, any excess cement was removed with a sharp instrument.

The same steps were followed for cementation with glass ionomer (Fuji 1) (GC Co, 76-1 HASUNUMA-CHO, ITABASHI-KU, Tokyo, Japan) and resin-modified glass ionomer cements (Fuji plus) (GC CORPORATION, 76-1 HASUNUMA-CHO, ITABASHI-KU, Tokyo, Japan).
Resin cement (Multilink N)(Ivoclar Vivadent AG, FL-9494Schaan/Liechtenstein) Metal/Zirconia Primer(Ivoclare Vivadent Schaan, Liechtenstein Germany) was applied with microbrush to the intaglio surface of the coping and allowed to react for 180 seconds, then dispersed with a strong steam of air. Multilink $\mathrm{N}$ was dispensed from the automix syringe, the desired quantity was applied directly onto the coping.

The copings were then seated on their corresponding implant-abutment assemblies using finger pressure then $5 \mathrm{Kg}$ load for 10 minutes by using the load applicator. Excess material was briefly light cured 1-2 seconds then removed easily with a scaler. Subsequently, all margins were light cured for 20 seconds. All specimens were then kept in an incubator $37^{\circ} \mathrm{C}$ for $24 \mathrm{hrs}$.

\section{Thermocycling}

In order to mimic the intra- oral conditions, the cemented copings were subjected to thermal cycling $48 \mathrm{hs}$ after cementation. Thermal cycling was performed for 1000 cycles between $5^{\circ} \mathrm{C}$ and $55^{\circ} \mathrm{C} \pm$ $2^{\circ} \mathrm{C}$ For 30 seconds in each dwelling temperature.

\section{Testing procedures:}

\section{A) Marginal accuracy:}

Vertical marginal gap (the gap distance starting from the finishing line to the external surface of the crown margin) was tested before and after cementation using a stereomicroscope (SZ-PT, Olympus,Japan). Each coping was then placed on the corresponding implant-abutment assembly to check its seating accuracy before microscopic measurements. Four guiding vertical lines equidistant were made on both the coping and epoxy resin blocks using an indelible pen to provide fixed points for vertical marginal gap distance measurement. For each coping, the pre-determined points corresponding to previously established guiding vertical lines were captured by CCD digital 
camera (DP10, Olympus, Japan) mounted on a stereomicroscope.The microscopic field included in the analysis was representative for the area related to the gap at the abutment- crown interface, which is the vertical gap distance. Different readings for each crown at the area of abutment/coping interface were calculated using the image analysis software program (Image J,1.29Z NIH, USA).

\section{B) Retention test:}

A universal testing machine (Lloyd Instruments LR5K, Steyning Way, Bognor Regis ,West Sussex, PO22 9ST) was used. Each coping was attached to the upper moving part of the testing machine by means of a stainless steel hook, while the resin base of the sample was engaged to the lower stationary part of the machine. The cemented copings were subjected to tensile force with a cross- head speed of $0.5 \mathrm{~mm} / \mathrm{min}$. The load required in Newton(N) to de-cement each coping was recorded and mean values for each group were calculated. The obtained data were tabulated and statistically analyzed.

\section{RESULTS}

The collected data was revised, tabulated and introduced to a PC using Statistical package for Social Science (SPSS 15.0 for windows; SPSS Inc, Chicago, IL, 2001). Data were presented and suitable analysis was done according to the type of data obtained for each parameter.

\section{Retention}

There were statistically significant differences between the different cements as regard retention. The mean of rentention values for resin modified glass ionomer was the highest, followed by resin cement, zinc phosphate and glass ionomer. Table(1), figure 1. One-Way ANOVA Post Hoc Tests showed no significant difference between resin modified glass ionomer, resin cement and zinc phosphate. Table (2).
Table (1): One-way ANOVA multiple comparisons between the different cements regarding retention in $(N)$.

\begin{tabular}{|c|c|c|c|c|c|}
\hline Retention & Mean & SD & F & P Value & Sig. \\
\cline { 1 - 3 } Zinc phosphate & 403.33 & 179.7 & & & \\
\cline { 1 - 3 } Glass ionomer & 244.05 & 73.9 & \multirow{2}{*}{2.92} & 0.05 & $\mathrm{~S}$ \\
\cline { 1 - 3 } Resin cement & 428.72 & 181.0 & & & \\
\cline { 1 - 3 } $\begin{array}{c}\text { Resin modified } \\
\text { glass ionomer }\end{array}$ & 429.46 & 195.0 & & & \\
\hline
\end{tabular}

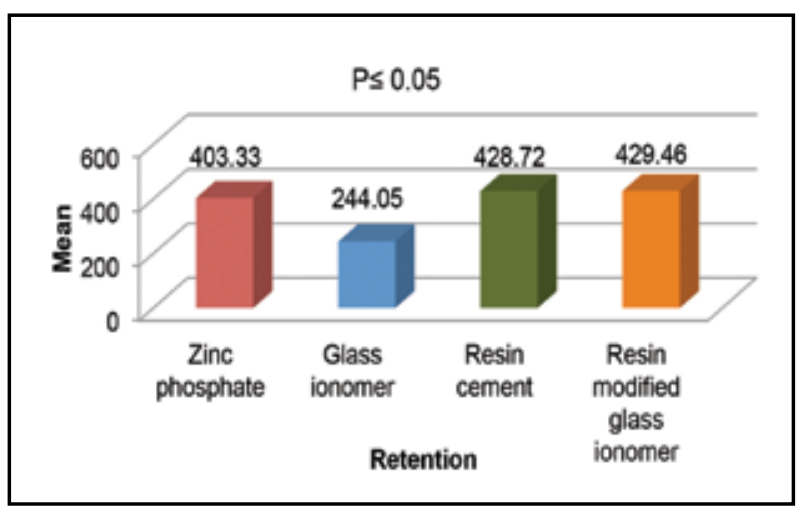

Fig. (1) Column chart of multiple comparisons between the different cements regarding retention in $\mathrm{N}$.

Table (2) One-Way ANOVA Post Hoc multiple comparisons between the different cements significance as regard retention in $N$ :

\begin{tabular}{|c|c|c|c|c|}
\hline (I) & $(\mathrm{J})$ & $\begin{array}{c}\text { Mean } \\
\text { difference } \\
(\mathrm{I}-\mathrm{J})\end{array}$ & $\begin{array}{c}\mathrm{P} \\
\text { Value }\end{array}$ & Sig. \\
\hline $\begin{array}{c}\text { Resin modi- } \\
\text { fied glass } \\
\text { ionomer }\end{array}$ & Zinc phosphate & 26.1 & $0.7 \mathrm{~ns}$ & $\mathrm{NS}$ \\
\cline { 2 - 5 } & Glass ionomer & 185.4 & 0.02 & $\mathrm{~S}$ \\
\cline { 2 - 5 } & Resin cement & 0.7 & $1.0 \mathrm{~ns}$ & $\mathrm{NS}$ \\
\hline Resin cement & Zinc phosphate & 25.4 & $0.7 \mathrm{~ns}$ & $\mathrm{NS}$ \\
\cline { 2 - 5 } & Glass ionomer & 184.7 & 0.02 & $\mathrm{~S}$ \\
\hline \multirow{2}{*}{$\begin{array}{c}\text { Zinc phos- } \\
\text { phate }\end{array}$} & Glass ionomer & 159.3 & 0.04 & $\mathrm{~S}$ \\
\hline
\end{tabular}




\section{Marginal adaptation}

Paired-Samples $\mathrm{T}$ Test showed that, the means of marginal adaptation after cementation for zinc phosphate, glass ionomer, resin cement and resin modified glass ionomer were higher than that for before cementation and those differences were statistically highly significant . Table(3)

Table (3): Comparison between different cements as regard marginal adaptation in $\mu \mathrm{m}$ before and after cementation:

\begin{tabular}{|c|c|c|c|c|c|c|c|}
\hline \multicolumn{2}{|c|}{ Marginal adaptation } & $\mathrm{N}$ & Mean & $\mathrm{SD}$ & $\mathrm{t}$ & $\begin{array}{c}\mathrm{P} \\
\text { Value }\end{array}$ & Sig. \\
\hline $\begin{array}{c}\text { Zinc } \\
\text { phosphate }\end{array}$ & before & 10 & 37.50 & 7.5 & & & \\
\cline { 2 - 8 } & after & 10 & 78.69 & 8.9 & -9.75 & 0.00 & $\mathrm{HS}$ \\
\hline $\begin{array}{c}\text { Glass iono- } \\
\text { mer }\end{array}$ & before & 10 & 30.89 & 7.7 & & & \\
\cline { 2 - 8 } & after & 10 & 56.35 & 16.3 & -6.45 & 0.00 & HS \\
\hline $\begin{array}{c}\text { Resin ce- } \\
\text { ment }\end{array}$ & before & 10 & 35.24 & 8.4 & -13.08 & 0.00 & HS \\
\cline { 2 - 8 } & after & 10 & 57.56 & 11.3 & & & \\
\hline $\begin{array}{c}\text { Resin mod- } \\
\text { ified glass } \\
\text { ionomer }\end{array}$ & before & 10 & 35.08 & 6.8 & & & \\
\cline { 2 - 8 } & after & 10 & 68.72 & 10.3 & & 0.00 & HS \\
\hline
\end{tabular}

There were statistically significant differences between the different cements as regard marginal gap. The mean of marginal gap for zinc phosphate was the highest, followed by resin modified glass ionomer, glass ionomer and resin cement (Table(4) ,Figure(2)). One-Way ANOVA Post Hoc tests showed the mean difference of marginal gap for \{zinc phosphate vs. resin cement\} and zzinc phosphate $v s$. glass ionomer $\}$ were statistically highly significant. The mean differences of marginal gap for, \{zinc phosphate vs. resin modified glass ionomer $\}$, \{resin modified glass ionomer $v s$. glass ionomer\} and \{glass ionomer $v s$. resin cement\} were not statistically significant. It was statistically significant for resin modified glass ionomer $v s$. resin cement $\}$.Table(5)
Table (4): One-way ANOVA multiple comparisons between the different cements as regard marginal gap in $\mu \mathrm{m}$

\begin{tabular}{|c|c|c|c|c|c|}
\hline Marginal gap & Mean & SD & $\mathrm{F}$ & $\begin{array}{c}\mathrm{P} \\
\text { Value }\end{array}$ & Sig. \\
\hline Zinc phosphate & 41.19 & 13.4 & \multirow[t]{4}{*}{5.63} & \multirow[t]{4}{*}{0.003} & \multirow[t]{4}{*}{ HS } \\
\hline Glass ionomer & 25.46 & 12.5 & & & \\
\hline Resin cement & 22.31 & 5.4 & & & \\
\hline $\begin{array}{c}\text { Resin modified glass } \\
\text { ionomer }\end{array}$ & 33.64 & 12.2 & & & \\
\hline
\end{tabular}

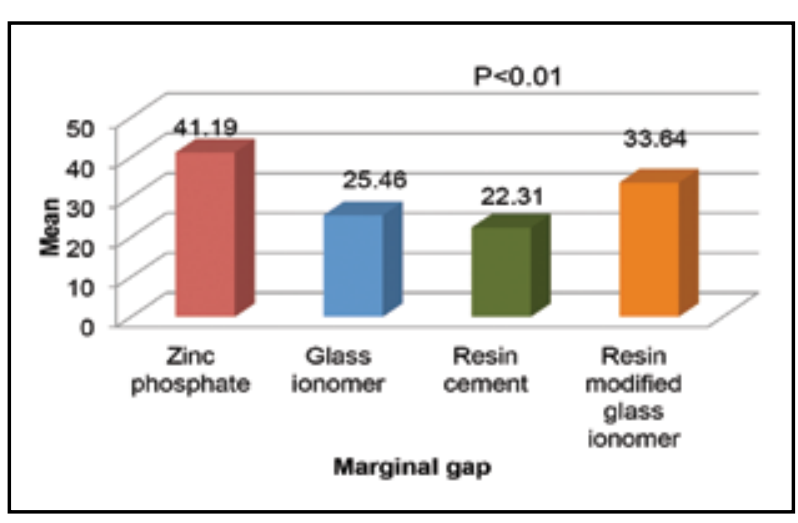

Fig. (2) Multiple comparisons between the different cements regarding marginal gap in $\mu \mathrm{m}$.

Table 5: One-Way ANOVA Post Hoc multiple comparisons between the different cements as regard marginal gap in $\mu \mathrm{m}$

\begin{tabular}{|c|c|c|c|c|}
\hline \multirow{2}{*}{$(\mathrm{I})$} & $(\mathrm{J})$ & $\begin{array}{c}\text { Mean dif- } \\
\text { ference } \\
(\mathrm{I}-\mathrm{J})\end{array}$ & P Value & Sig. \\
\hline \multirow{3}{*}{ Zinc phosphate } & Glass ionomer & 15.7 & 0.004 & $\mathrm{HS}$ \\
\cline { 2 - 6 } & Resin cement & 18.9 & 0.001 & $\mathrm{HS}$ \\
\cline { 2 - 6 } & $\begin{array}{c}\text { Resin modified } \\
\text { glass ionomer }\end{array}$ & 7.6 & 0.1 & $\mathrm{NS}$ \\
\hline \multirow{2}{*}{$\begin{array}{c}\text { Resin modified } \\
\text { glass ionomer }\end{array}$} & Glass ionomer & 8.2 & 0.1 & \\
\cline { 2 - 6 } & Resin cement & 11.3 & 0.03 & $\mathrm{~S}$ \\
\hline Glass ionomer & Resin cement & 3.1 & 0.5 & $\mathrm{NS}$ \\
\hline
\end{tabular}




\section{DISCUSSION}

Since marginal adaptation and retention are among the main criteria for success of a restoration, they need to be thoroughly investigated upon evaluation of implant supported crowns. In this in vitro study, cement failure load and marginal adaptation were evaluated on single- unit castings cemented to implant abutments. Four different luting agents were tested using thermal cycling to simulate the intraoral environment. In this study, the null hypotheses were rejected as there were differences in retentiveness and marginal adaptation among the metal copings cemented with different luting agents. The resin modified glass ionomer cement had the highest retention, but there were no significant differences between it and both of resin cement and zinc phosphate cement. In the study of Nejatidanesh et $\mathrm{al},{ }^{(4)}$ they compared the retentive strength of different luting agents to cement base metal alloy crowns to implant abutments. The results were in accordance with this study.

Many studies ${ }^{(5-7)}$ has indicated that the retentive strength of resinous cement is superior to that of, zinc phosphate and zinc polycarboxylate cements. The higher retentive strength of the resin cements was attributed to the differences in adhesive system used. Furthermore, resin modified glass ionomer cement adheres to metal by chelating metallic ions, but the retentive strength may be weakened by early water contact $^{(6)}$ which can be avoided in the oral cavity by application of varnish.

The retention of titanium copings over short ITI solid abutments using Zinc phoshate and Panivia 21 was studied ${ }^{(8)}$. The highest retentive value was obtained with panavia 21.This finding was in accordance with another study ${ }^{(9)}$. A combination of Panavia 21 and titanium alloy was reported to have higher bond strength compared to other alloys ${ }^{(10,11)}$. Panavia cement contains a phosphate monomer, 10-methacryloxydecyl dihydrogen phosphate (MDP) (also present in alloy primer), which facili- tates chemical bonding to non-precious metals ${ }^{(1)}$.In the study of sheets et al, ${ }^{(12)}$ they compared the retentive strengths of different luting agents used to cement base metal alloy copings to implant abutments. Zinc phosphate and resin modified glass ionomer cements showed the same retention strength ${ }^{(12)}$ .With regard to the CeraOne system, zinc phosphate cement had highest retention value, and resinous cement presented statistically similar retentive strength $^{(13)}$.Squier et al, ${ }^{(14)}$ reported a higher retentive value for Panavia than zinc phosphate and resin modified glass ionomer, which differs from the current study. This discrepancy may be related to sandblasting and surface conditioning in this study.

Glass ionomer cement had the lowest retention among the luting agents. This may come as some surprise to clinicians in considering the widespread use of glass ionomer cements for the cementation of natural tooth crowns. This finding is consistent with a previous studies that demonstrated that glass ionomer cement showed significantly lower retention than zinc phosphate and resinous cements, and similar retention to zinc oxide cement without eugenol ${ }^{(13,15)}$.In the present study, no pretreatment was performed on the abutments, and glass ionomer cement does not adhere to an inert surface. Furthermore, the solubility of glass ionomer cement is more than that of other cements, and it is very susceptible to early water contact and desiccation ${ }^{(16)}$, which can dramatically reduce the mechanical properties of the cement ${ }^{(17)}$.

The debate on what type of cement to use for the cement-retained crown CRC technique continues. It was observed that the goal of studies is not to discover the "best" cement ${ }^{(6)}$. Rather, the goal is to "provide a ranking order of the cements in their ability to retain the castings". The clinician's opportunity to select from the retentiveness of various cements and apply it in an escalating fashion allows a sense of comfort and control when releasing the patient after insertion of the crown. The results of another study ${ }^{(12)}$ did not suggest that any cement is 
better than another at retaining CRCs to implant abutments or that a threshold value must be accomplished to ensure retention. The ranking of cements presented is meant to be a discretionary guide for the clinician in deciding the amount of desired retention between castings and implant abutments.

A survey of dental schools in the united states reported that $86 \%$ of program directors in advanced prosthodontics suggest sealing the screw access opening, and none recommended leaving this channel opened prior to cementation of the restoration ${ }^{(18)}$ .The recommendation provided by Straumann was to seal the abutment screw access channel with wax or gutta percha prior to crown cementation ${ }^{(3)}$. It may be possible that filling abutment screw access channels with composite resin, and indeed some other materials, affects crown coping retention ${ }^{(3)}$.In the current study, the abutment screw access channels were filled with cotton Pellets to cover the abutment screw and softened, compacted molding wax. In this manner, there was no possibility of a potential chemical bond between the material used to fill the abutment screw access channel and some cements.

Thermocycling is critical processes to imitate the oral environment in vivo. It may introduce interfacial stress due to differing coefficients of thermal expansion of the materials used ${ }^{(19)}$. The different results with the present study maybe due to using different cements and thermal cycles. Long-term thermal cycling has been shown to reduce the retentive strength of luting agents ${ }^{(5,6,14)}$. According to the ISO TR 11450, thermocycling 500 times in water at temperatures between 5 and $55^{\circ} \mathrm{c}$ is considered to be an appropriate test for aging dental materials ${ }^{(9)}$. In this study, thermocycling was applied 1000 times in water baths.

The marginal accuracy of the cemented crown is of clinical importance and influences long-term survival of the restorations ${ }^{(20)}$. Marginal fit of complete crown restorations and different cementation techniques influence definitive seating of the ce- mented prosthesis affecting not only periodontal status but also longevity ${ }^{(21)}$.The luting agents may influence the marginal discrepancy values by elevating the crown after cementation ${ }^{(22)}$.In this study, zinc phosphate had a larger mean marginal gap than the other three types of cements. This observation was attributed to the inherent higher film thickness of zinc phosphate cement, and particle agglomeration as a crown is seated and the cement tries to escape through a decreasing space .Further pressure causes partial separation of the cement into its basic phases, powder and liquid. The agglomeration of powder particles would then further prevent seating. The phenomenon is called the "filtration effect "of zinc phosphate cement ${ }^{(23)}$.

Multilink $\mathrm{N}$ resin cement exhibited the smallest mean marginal gap value. This finding is in contrast with several other studies which have shown that copings cemented with resins have the poorest seating ${ }^{(24-26)}$. A possible explanation for this result is that the setting reaction of the new resin cements may differ from that of conventional resin cements and apparently allows a longer working time to enable escape of excess cement. In the present investigation, a recently introduced universal luting composite system has been used. Multilink N which is a self-curing resin-based dental luting material with light-curing option. In the current study, the marginal discrepancy of the crowns cemented with glass ionomer cement was slightly greater than that of the crowns cemented with resin cement, but no significant differences were observed. This finding is in accordance with the result of Yüksel and Zaimoğlu's study ${ }^{(27)}$.This can be explained by the differences in viscosity of the cements ${ }^{(28-30)}$.

The tolerable misfit level that may prevent biological or mechanical failures of implant-supported restorations still remains unknown ${ }^{(31)}$ as there is no longitudinal clinical study that reports implant failure specifically ascribed to framework misfit ${ }^{(32)}$. Hence, various values have been proposed in the literature as the maximally acceptable marginal gap 
width depending on the type of restoration and the study. Some authors define clinically acceptable values for the marginal gap after cementation to be smaller than $150 \mu \mathrm{m}^{(33,34)}$. Others consider only marginal gap values of less than $120 \mu \mathrm{m}$ to be within the clinically acceptable limit ${ }^{(21,35)}$.However, discrepancies of all samples in this study are situated below $120 \mu \mathrm{m}$.

One limitation of our study was the use of a pure tensile test. The clinical stresses may not be represented by purely tensile test where other non-axial forces may contribute to crown decementation $^{(36)}$. However, the pure tensile testing was used because it represents the worst case clinical scenario, and has been adopted in other studies and could allow comparison of our results with previous investigations.

\section{CONCLUSIONS}

Within the limitations of the present study, the following conclusions could be drawn:

1- Resin-modified glass ionomer, zinc phosphate and resin cements almost have the same retentive quality and are recommended for definitive cementation of single implant- supported restorations.

2- Vertical marginal gap values of all tested cements were within the clinically acceptable range of less than $120 \mu \mathrm{m}$.

3- The use of resin cement resulted in the best marginal adaptation, whereas the use of zinc phosphate cement demonstrated the largest marginal gap.

\section{REFERENCES}

1- Comfort MB, Chu FC, Chai J, Wat PY and Chow TW.A 5 -year prospective study on small diameter screw- shaped oral implants. J Oral Rehabil 2005;32: 341-5.

2- Pameijer CH. A Review of Luting Agents. Int J of Dent. 2011; 2012: 1-7.
3- Dudley J E, Richards L C, Abbott J R. Retention of cast crown copings cemented to implant abutments. Aust Dent J 2008; 53: 332-9.

4- Nejatidanesh F, Savabi O, Ebrahimi M, Savabi G.Retentiveness of implant-supported metal copings using different luting agents. Dent Res J 2012;9(1):13-8.

5- Maeyama H, Sawase T, Jimbo R, Kamada K, Suketa N, Fukui J. Retentive strength of metal copings on prefabricated abutments with five different cements. Clin Implant Dent Relat Res. 2005;7:229-34.

6- Mansour A, Ercoli C, Graser G, Tallents R, Moss M. Comparative evaluation of casting retention using the ITI solid abutment with six cements. Clin Oral Implants Res. 2002;13:343-8.

7- Piwowarczyk A, Lauer HC, Sorensen JA. In vitro shear bond strength of cementing agents to fixed prosthodontic restorative materials. J Prosthet Dent 2004;92:265-73.

8- Sadig WM, Al Harbi MW.Effects of surface conditioning on the retentiveness of titanium crowns over short implant abutments. Implant Dent2007;16:387- 96.

9- Kunt GE, Ceylan G, Yilmaz N, Kucuk B E. Luting Agent Effectiveness on implant crown retention. int J Oral Implantol and Clin Res.2011;2(1):7-11.

10- Burke FJ, Fleming GJ, Nathanson D, Marquis PM. Are adhesive technologies needed to support ceramics? An assessment of the current evidence. J Adhes Dent 2002;4:7 22.

11- Kim Y, Yamashita J, Shotwell JL, Chong KH, Wang HL. The comparison of provisional luting agents and abutment surface roughness on the retention of provisional implantsupported crowns. J Prosthet Dent 2006;95:450-5.

12- Sheets JL, Wilcox C, Wilwerding T. Cement selection for cement-retained crown technique with dental implants. J Prosthodont. 2008;17:92-6.

13- Montenegro AC, Machado AN, Depes Gouvêa CV. Tensile strength of cementing agents on the CeraOne system of dental prosthesis on implants. Implant Dent. 2008;17:45160.

14- Squier RS, Agar JR, Duncan JP, Taylor TD.Retentiveness of dental cements used with metallic implant components. Int J Oral Maxillofac Implants. 2001;16:793-8.

15- Güncü MB, Cakan U, Canay S. Comparison of 3 luting agents on retention of implant- supported crowns on 2 different abutments. Implant Dent. 2011;20(5): 349-53. 
16- Powers JM, Sakaguchi RL. Cements. In: Powers JM, Sakaguchi RL, editors. Craig's Restorative Dental Materials. $12^{\text {th }}$ ed. St. louis: Mosby; 2006.p.480-511.

17- Shen C. [Dental Cements]. In: Anusavice KJ. Phillips Dental Materials. $11^{\text {th }}$ ed. Rio de Janeiro: Elsevier; 2005. p. 419-68.

18- Tarica DY, Alvarado VM, Truong ST. Survey of United States dental schools on cementation protocols for implant crown restorations. J Prosthet Dent 2010; 103: 68-79.

19- Pan Y-H, Ramp LC, Lin C-K, Liu P-R. Comparison of 7 luting protocols and their effect on the retention and marginal leakage of a cement-retained dental implant restoration. Int J Oral Maxillofac Implants. 2006;21:587-92.

20- Pilathadka S, Slezák R, Vahalová D, Kudiyirickal MG, Sukumar S . Influence of different luting agents on the marginal discrepancy of procera all ceram alumina crown copings - an experimental study acta medica 2008;51(1):13-18.

21- Quintas AF, Oliveira F, Bottino MA . Vertical marginal discrepancy of ceramic copings with different ceramic materials, finish lines, and luting agents: An in vitro evaluation. J Prosthetic Dent 2004; 92:250-7.

22- Yüksel E , Zaimoğlu A. Influence of marginal fit and cement types on microleakage of all-ceramic crown systems. Braz Oral Res. 2011;25(3):261-6 .

23- Yeung TC, Lai YL, Hsieh YL, Lee SY. The effect of cement and venting design on the retentive strength and marginal adaptation of CeraOne implant prostheses. Chin Dent J 2005;24(2):95-100.

24- Castillo-Oyagüe R, Lynch CD, Turrión AS, López-Lozano JF, Torres-Lagares D, Suárez-García MJ. Misfit and microleakage of implant-supported crown copings obtained by laser sintering and casting techniques, luted with glassionomer, resin cements and acrylic/urethane-based agents. J Dent. 2013;41(1):90-6.

25- Bottino MA, Valandro LF, Buso L, özcan M .The influence of cervical finish line, internal relief, and cement type on the cervical adaptation of metal crowns.Quintessence Int 2007;38:e425-32.
26- Pattanaik BK, Nagda S J. An evaluation of retention and marginal seating of $\mathrm{Ni}-\mathrm{Cr}$ alloy cast restorations using three different luting cements: An in vitro study. Indian J Dent Res 2012;23:20-5.

27- Yüksel E , Zaimoğlu A. Influence of marginal fit and cement types on microleakage of all-ceramic crown systems. Braz Oral Res. 2011;25(3):261-6 .

28- Gu XH, Kern M. Marginal discrepancies and leakage of all ceramic crowns: Influence of luting agents and aging conditions. Int J Prosthodont. 2003 ;16(2): 109-16.

29- Gonzalo E, Suarez MJ, Serrano B, Lozano JFL. A comparison of the marginal vertical discrepancies of zirconium and metal ceramic posterior fixed dental prostheses before and after cementation. J Prosthet Dent. 2009;102(6):378-84.

30- Balkaya MC, Cinar A, Pamuk S. Influence of firing cycles on the margin distortion of 3 all ceramic crown systems. $\mathrm{J}$ Prosthet Dent 2005;93:346-55.

31- Karl M, Winter W, Taylor TD, Heckmann SM. In vitro study on passive fit in implant-supported 5-unit fixed partial dentures. Int J Oral Maxillofac Implants. 2004;19:30-7.

32- Sahin S, Cehreli MC. The significance of passive framework fit in implant prosthodontics: current status. Implant Dent. 2001;10:85-92.

33- Tinschert J, Natt G, Mautsch W, Spiekermann H, Anusavic K J. Marginal fit of alumina and zirconia - based fixed partial dentures produced by a CAD/ CAM system. Oper. Dent. 2001; 26:367-74.

34- McLean JW, von Fraunhofer JA. The estimation of cement film thickness by an in vivo technique. Br Dent $\mathrm{J}$ 1971;131:107-11.

35- Kokubo Y, Ohkubo C, Tsumita M, Miyashita A, Steyern P V, Fukushima S. Clinical marginal and internal gaps of Procera ALLCeram crowns. J Oral Rehab 2005;32: 526- 30 .

36- Kaar D, Oshida Y, Andres CJ, Barco MT, Platt JA. The effect of fatigue damage on the force required to remove a restoration in a cement-retained implant system. J Prosthodont2006;15:289-294. 